
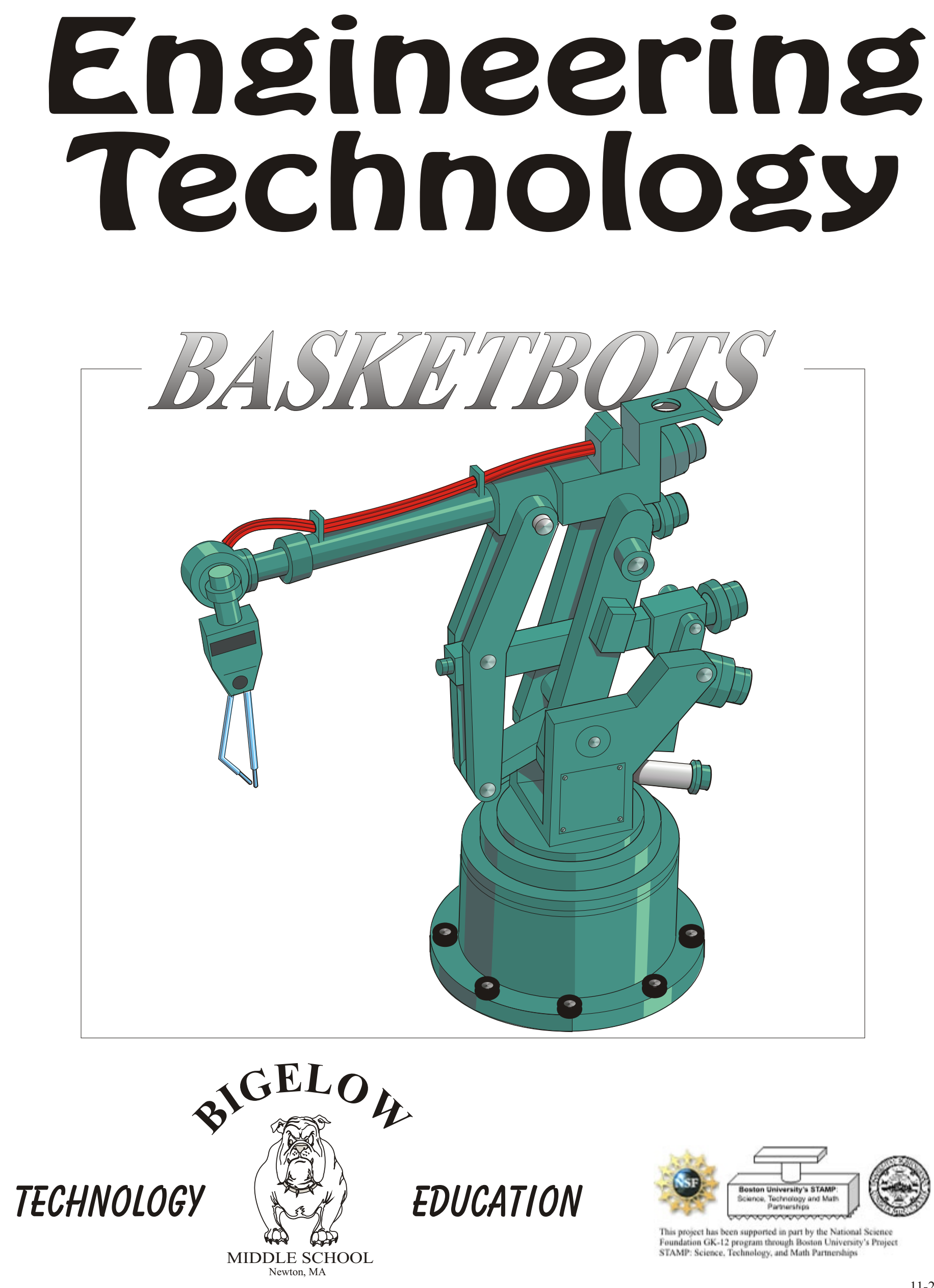


\section{PROBLEM GUIDELINES}

Your challenge is to design a robotic arm that will lift a ping pong ball from a storage area to a basket located 12" off the ground. You will only be able to use the materials provided and you will have a limited time frame to complete the task. Each member of your group needs to participate in each step of the process. Points will be awarded each time a team correctly completes a stage in the process. If a team fails to correctly complete a step, they must redo that step.

1. The robotic arm can stand no taller than 24 " before it is in its extended position

2. No more than 8 syringes may be used in the construction of the robotic arm

3. Your robotic arm must be able to rotate at least $90^{\circ}$ from its original position

4. The size of the base of the robotic arm must not be altered in any way (supplied by teacher)

5. The syringe control panel must not be altered in any way (supplied by teacher)

6. Each group must submit a completed design packet before they can participate in the final competition

\section{When you meet as a team you should:}

- Review the problem.

- Review the specifications.

- Each team member should draw at least two thumbnail sketches of possible robot arm designs.

- Meet as a group and review all of the thumbnail drawings from each of your team members

- Select one final design and each team member needs to draw that design on the final design sheet.

(The final design may be a combination of many designs)

-HINT: Keep the design simple! Sometimes the best solution is the simplest one.

\section{tools}

\section{band saw \\ drill press}

file

sand paper coping saw

hack saw

X-acto knife

rulers try square

compass

wire cutterss

sander

\section{materials}

rigid insulation

dowels

tape

glue

rubber bands wood

syringes

1/8" tubing

cardboard

pins nuts / bolts

zip ties

hinges

plastic

Ping Pong balls 
NAME:

CLASS:

DESIGN SHEET

Team Members:

Step 1 Identify the need or the problem

What do we have to do?

Standards we must meet:

Maximum height:

Maximum \# of syringes::

Minimum rotation angle:

What can not be altered?

\section{Step 2 Research the need or problem}

Use the back side of this worksheet to do your research

Step 3 Develop possible solutions

Draw at least 2 possible solutions (thumbnail drawings)

\section{sketch 1}


Team Members:

\section{Step 2 Research the need or problem}

What is Bioengineering?

List 3 practical applications of Bioengineering

Who works with Bioengineering?

What is a Robot?

How do robots relate to Bioengineering?

List 3 ways robots are used

What is Hydraulics?

List 3 ways hydraulics is used in our everyday lives

What is Pneumatics?

List 3 ways pneumatics is used in our everyday lives 
NAME:

CLASS:

\section{FINAL DESIGN}

\section{Step 4: Select the best possible solution}

Include dimensions and the materials you plan to use.

\section{final design}

Step 5: Construct a prototype of your solution

List the steps you took to build your robotic arm (Also write down any idea changes you have while you build)

Step 6: Test and evaluate your solution

Test your arm on the playing field (what is wrong?)

List how you intend to fix the problems 
NAME:

CLASS:

\section{RE-DESIGN \& EUALUATE}

Step 7: Communicate the solution

Test your arm with all four members of your group. List any needed changes or adjustments.

Observations

List any changes or adjustments

Step 8: Redesign and / or rebuild

List any and all changes that you made to your robotic arm

Step 9: Evaluation

What was the best improvement that you made to your robotic arm?

What was your worst design idea? Explain why?

If there were a "next time" what design changes would you make?

Explain how teamwork was essential to controlling the robotic arm?

How did your team use mechanical advantage to accomplish a task with your robot?

List the 9 steps of the design process

1.

2.

3.

4.

5.

6.

7.

8.

9. 


\section{Answer the following questions as completely as you can}

1. How are robotic arms utilized in Bioengineering?

2. Why was water used instead of air for our robotic arms?

3. List the 4 parts of your robot that each syringe controlled.

4. List 2 ways that robots are able to move.

1 .

2.

5. What is hydraulics?

6. List 2 ways that hydraulics are used in our world.

1.

2.

7. What is pneumatics?

8. List 2 ways that pneumatics are used in our world.

1.

2.

9. How would using different sized syringes allow you to gain mechanical advantage?

10. How far would a $60 \mathrm{~mL}$ syringe extend if it were controlled by a full $10 \mathrm{~mL}$ syringe?
a. $1 / 6$
b. $1 / 4$
c. $1 / 2$
b. all the way

11. What is the problem with having air bubbles present in the tubing?

12. Why is group communication so important when trying to control your robot arm?

13. How is your brain similar to your whole group when controlling your robot?

14. Match the parts of the robots with simalar parts of the human body.

dowel

Long support shafts

tubing

syringes

Control Panel (group)

"Pinchers" or "grippers"

$\begin{array}{ll}\text { 1. } & \text { hand/fingers } \\ \text { 2. } & \text { nerves } \\ \text { 3. } & \text { brain } \\ \text { 4. } & \text { joints } \\ \text { 5. } & \text { muscles } \\ \text { 6. } & \text { arm }\end{array}$

15. List 2 problems your group encountered during the competition. 


\section{Teacher Materials}

Connection to frameworks.

9

Fluids Demonstration (Page 1)

Fluids Demonstration (Page 2).......................................11

Fluids Demonstration (Page 3).......................................12

Fluids Demonstration (overhead original)......................13

Robotics Links..............................................................14

Finding Gear Ratios.......................................................15

Finding Gear Ratios - 2.....................................................16

Finding Gear Ratios - 3...................................................17

Teamwork Evaluation Form................................................18

Teamwork Evaluation Form - Example.............................19

Individual Strengths Worksheet.......................................20

Individual Strengths Worksheet Example........................21 


\section{Connection to Frameworks}

Upon completion of this TLA (Technology Learning Activity) students will

have learned and / or demonstrated the following Frameworks Standards:

\section{Materials, Tools, and Machines}

1.1 Given a design task, identify appropriate materials (e.g., wood, paper, plastic, aggregates, ceramics, metals, solvents, adhesives) based on specific properties and characteristics (e.g., weight, strength, hardness, and flexibility).

1.2 Identify and explain appropriate measuring tools, hand tools, and power tools used to hold, lift, carry, fasten, and separate, and explain their safe and proper use.

1.3 Identify and explain the safe and proper use of measuring tools, hand tools, and machines (e.g., band saw, drill press, sanders, hammer, screwdriver, pliers, tape measure, screws, nails, and other mechanical fasteners) needed to construct a prototype of an engineering design.

\section{Engineering Design}

2.1 Identify and explain the steps of the engineering design process, i.e., identify the need or problem, research the problem, develop possible solutions, select the best possible solution(s), construct a prototype, test and evaluate, communicate the solution(s), and redesign.

2.2Demonstrate methods of representing solutions to a design problem, e.g., sketches, orthographic projections, multi-view drawings.

2.3 Describe and explain the purpose of a given prototype.

2.4 Identify appropriate materials, tools, and machines needed to construct a prototype of a given engineering design.

2.5Explain how such design features as size, shape, weight, function, and cost limitations would affect the construction of a given prototype.

2.6 Identify the five elements of a universal systems model: goal, inputs, processes, outputs, and feedback.

\section{Communication Technologies}

3.2 Identify and explain the appropriate tools, machines, and electronic devices (e.g., drawing tools, computer-aided design, and cameras) used to produce and/or reproduce design solutions (e.g., engineering drawings, prototypes, and reports).

3.3 Identify and compare communication technologies and systems, i.e., audio, visual, printed, and mass communication.

3.4 Identify and explain how symbols and icons (e.g., international symbols and graphics) are used to communicate a message.

\section{$7 \quad$ Bioengineering Technologies}

7.1Explain examples of adaptive or assistive devices, e.g., prosthetic devices, wheelchairs, eyeglasses, grab bars, hearing aids, lifts, braces.

7.2Describe and explain adaptive and assistive bioengineered products, e.g., food, bio-fuels, irradiation, integrated pest management. 


\section{FLUIDS DEMONSTRATION}

Overall educational objective: Students will learn about the two kinds

of fluids: liquids and gases. Students will understand that liquids (water),

unlike gases (air), cannot be compressed. This property makes them ideal for hydraulic work

applications.

\section{Materials list:}

- 1 - Hydraulic/pneumatic lift stand (4 different sized cylinders mounted securely)

- 9 - Pick-up kits containing various pick-up items (balls, models, matchbox cars, etc.)

- Deposit cylinders (small coffee can)

- 4 - Bottles of colored water (used plastic drinking water bottles)

- Film canisters (25)

- Food coloring (4 colors)

- Syringes (4 sizes, $20 \mathrm{cc}, 30 \mathrm{cc}, 40 \mathrm{cc}, 60 \mathrm{cc})$

- Tools (usual fabrication lab tools)

- Scissors

\section{Lesson activities:}

Have two students use the hydraulic/pneumatic lift stand to demonstrate the power of water and air. Explain that we use air and water to do work. When air is used, it is called PNEUMATICS. When water or liquid is used, it is called HYDRAULICS. Have the students brainstorm how they have seen pneumatics and hydraulics used to do work. Write the ideas on the overhead. (examples of pneumatics: dental drill, paint sprayer, nail or staple guns, wrenches at the auto shop, BB guns. hydraulics: automobile brakes, car lifts at the auto shop, hydraulic presses (stamp or shape metals)

Have two new students demonstrate the hydraulic/pneumatic lift stand by pushing the syringes in and out in a fast pace. (Caution them not to break the syringes) Have the students identify the differences between the water and air. (Water moves quicker, and goes higher. Air moves slower, and doesn't go as high.) Have one student attempt to resist the lifting power of the liquid syringe by holding the syringe on the stand at the bottom of its range of travel while the other student pushes on the hand-held syringe. Have the same student repeat this process with the air filled syringes.

Have the students speculate on what causes the differences between water and air. Explain that air molecules compress (squash together) more than water does, causing the lift to work less efficiently (bottle not lifted as high, motion less smooth). Water (liquids) are more efficient. How do these differences affect the work that air and water do? Refer to the list on the overhead. Have the students come up with some similarities between the different kinds of work water does (moving or supporting heavy materials, a large force needs to be supplied over a long period of time). Have the students come up with some similarities between the different kinds of work air does (moderate force over a very short period of time, moving or supporting light materials). 


\section{Teacher's Copy}

\section{FLUIDS DEMONSTRATION - 2}

Divide the students into teams of four (one or two groups may have three students

if necessary). Have each team move to the wooden test robot arm. Go over the parts of the robot as a class:

Rotating Base, Shoulder, Arm, and Gripper. Have each student hold one of the four syringes on the robot.

(With teams of three, one student will need to hold two syringes.)

Allow 5-10 minutes for the students to practice gripping and placing the materials (supplied in the pick-up kits) into the deposit cylinder.

Prepare a series of tasks you would like the students to perform. Make sure the teams understand they must complete the tasks in order without touching the items.

Review the successes and role of cooperation among the teams. Have the students hypothesize how the robot would work if air were used instead of water. (Harder to control, less effective over distance, smaller range of movement).

Call attention to the career fields that are related to this module. Discuss how students might prepare for occupations that interest them.

Teacher tips: Make the following chart on the board, use as a handout, or make an overhead of the original supplied (Fluids overhead 1) when teaching about pneumatics and hydraulics:

\begin{tabular}{|c|c|c|}
\hline Ways we use air and water & Advantages & Disadvantages \\
\hline Pneumatics & & \\
\hline Hydraulics & & \\
\hline
\end{tabular}

Possible Classroom Extension:

- Have a career day when parents that use pneumatics and/or hydraulics at work can demonstrate equipment at school.

- Have students research careers that relate to pneumatics or hydraulics technology.

\section{Safety precautions:}

- Caution the students not to pull the plungers out of the syringes, and advise them not to push or pull too fast or too hard. If a plunger is pulled out, simply refill the syringe with colored water. The syringes work best when you can get all of the air bubbles out of the syringes and the tubing. 


\section{References:}

National Geographic v192, July '97, p.76-95 "Robot Revolution" Discusses

current trends in robot technology and some of the problems currently facing researchers and developers.

\section{Videos:}

Lets Talk Robotics NASA Liftoff to Learning Series http://robotics.nasa.gov/

\section{Extra Credit Activities:}

\section{http://www.bigelowmiddleschool.com/programs/Teched/engineering/}

\section{Career Fields:}

- Engineering, Bioengineering, Manufacturing, Bio Medical, Construction, Dentistry, Science, Technical.

\section{Sample Occupations:}

- Robotics Engineer: Plan, design, and build robots and other related products. They also plan and design computer systems tailored for individual robots. They might also install these systems or modify already existing ones.

\section{Education: Bachelor's Degree}

- Hydraulics Engineer: Use hydraulic mechanics along with other forms of engineering to design equipment that utilizes the force of hydraulics to move objects such as automobile lifts, bulldozer blades, dump truck bodies, automobile brake systems,

\section{Education: Bachelor's Degree}

- Mechanical Engineer: They plan and design tools, engines, machines, and other mechanical equipment. They design and develop power-producing machines such as internal combustion engines, steam and gas turbines, and jet and rocket engines. They also design and develop power-using machines such as refrigeration and air-conditioning equipment, robots, machine tools, materials handling systems, and industrial production equipment.

Education: Bachelor's Degree 


\section{Teacher's Copy}

FLUIDS Overhead 1

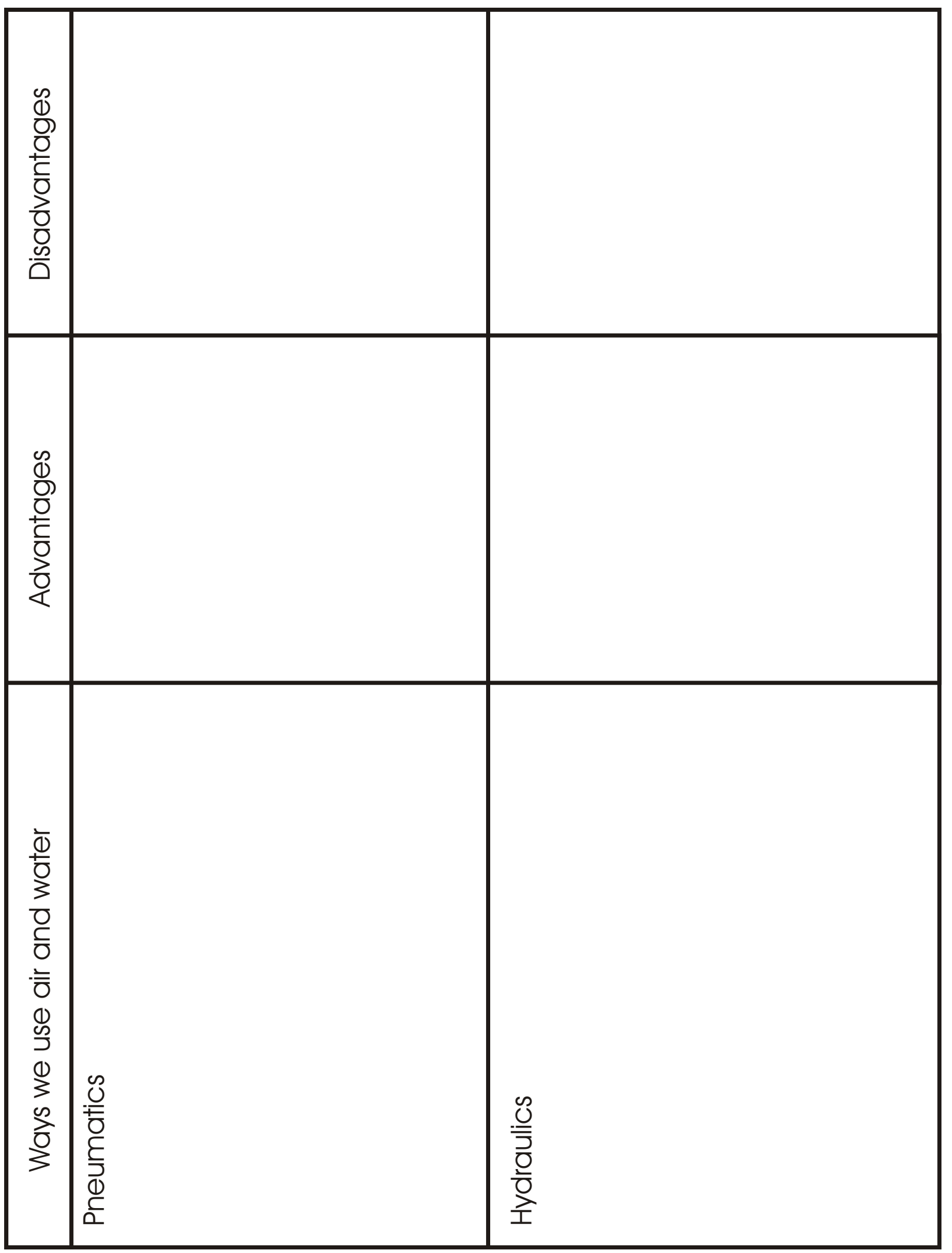


Lego Mindstorms kits

http://mindstorms.lego.com/eng/default.asp

First Lego

http://www.usfirst.org/

Autonomous Robotics Research Group

http://www.cs.siue.edu/robotics/

etoys,com purchase Lego Mindstorms

http://www.etoys.com

KISS institute for practical robots

http://www.kipr.org/

NASA Robotics

http://robotics.nasa.gov/

Educational Robotics Matrix

http://robotics.nasa.gov/matrix.htm

Pre K-12 Engineering

http://www.prek-12engineering.org/default.asp

Massachusetts Engineering Frameworks (interactive)

http://www.prek-12engineering.org/frameworks/6-8.asp

Junior Engineering Lesson Plans

http://www.engineering.usu.edu/jrestate/lessons/lesson.htm

Robotics Technology.com

http://www.robotics-technology.com

Surfing the net with kids Robots

http://www.surfnetkids.com/robots.htm

Museum of Science Interactive

http://www.tcm.org/index.html

Design your own robot on line (Museum of Science)

http://www.mos.org/exhibits/robot/activities-pre.html

How robots work

http://howstuffworks.lycoszone.com/robot.htm/printable 
The following material lists are for one group of 4 students. The testing equipment will be shared by the whole class. You simply need to multiply the totals by the number of groups in your classes.

\section{Robot Arm Material Kits (given to each group)}

1 Basketbots Student Design Packet (download)

$63 / 8$ " x 3/4" x 16 " (length can vary) pine strips

$2 \quad 1 / 4 " x 12 "$ dowels (hinges/pivots)

$13 / 4 " \times 2 " \times 6$ " scrap pine

$13 / 4 " \times 8$ " 13 " pine (base of robot)

$13 / 4 " x 9 " \times$ 9" pine (mounting bracket (size may not be altered)

$1 \quad 1$ " 2 " x 16 " rigid foam insulation

12 " 12 " x 16 " rigid foam insulation

$4 \quad 1 / 2$ "cup hooks (retracting base rotation)

4 rubber bands (retracting base rotation)

$2 \quad 10 \mathrm{ml}$ syringes

$20 \mathrm{ml}$ syringes

$230 \mathrm{ml}$ syringes

$260 \mathrm{ml}$ syringes

436 " pieces of $1 / 8$ " I.D. clear rubber tubing

\section{Community supplies}

wood Glue

hot melt glue guns and glue

nails

screws

duct tape band saw

jig saw

hand tools

sand paper

belt/disc sander

\section{Testing Equipment}

1 Competition court*

24 Ping pong balls

1 stop watch

1 group testing sheet (download)

1 tournament bracket sheet (download) 


\section{FINDING GEAR RATIOS - 2}




\section{FINDING GEAR RATIOS - 3}

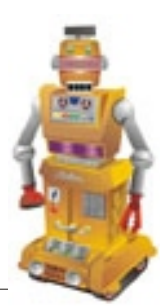

17 
TEAMWORK EUALUATION FORM 
EUALUATION FORM - EXAMPLE

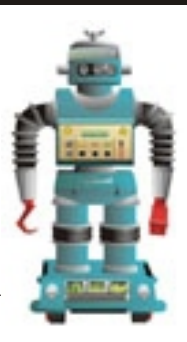

19 


\section{INDOUIDUAL STRENGTHS WORKSHEET}

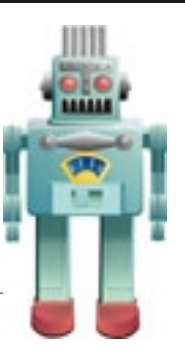




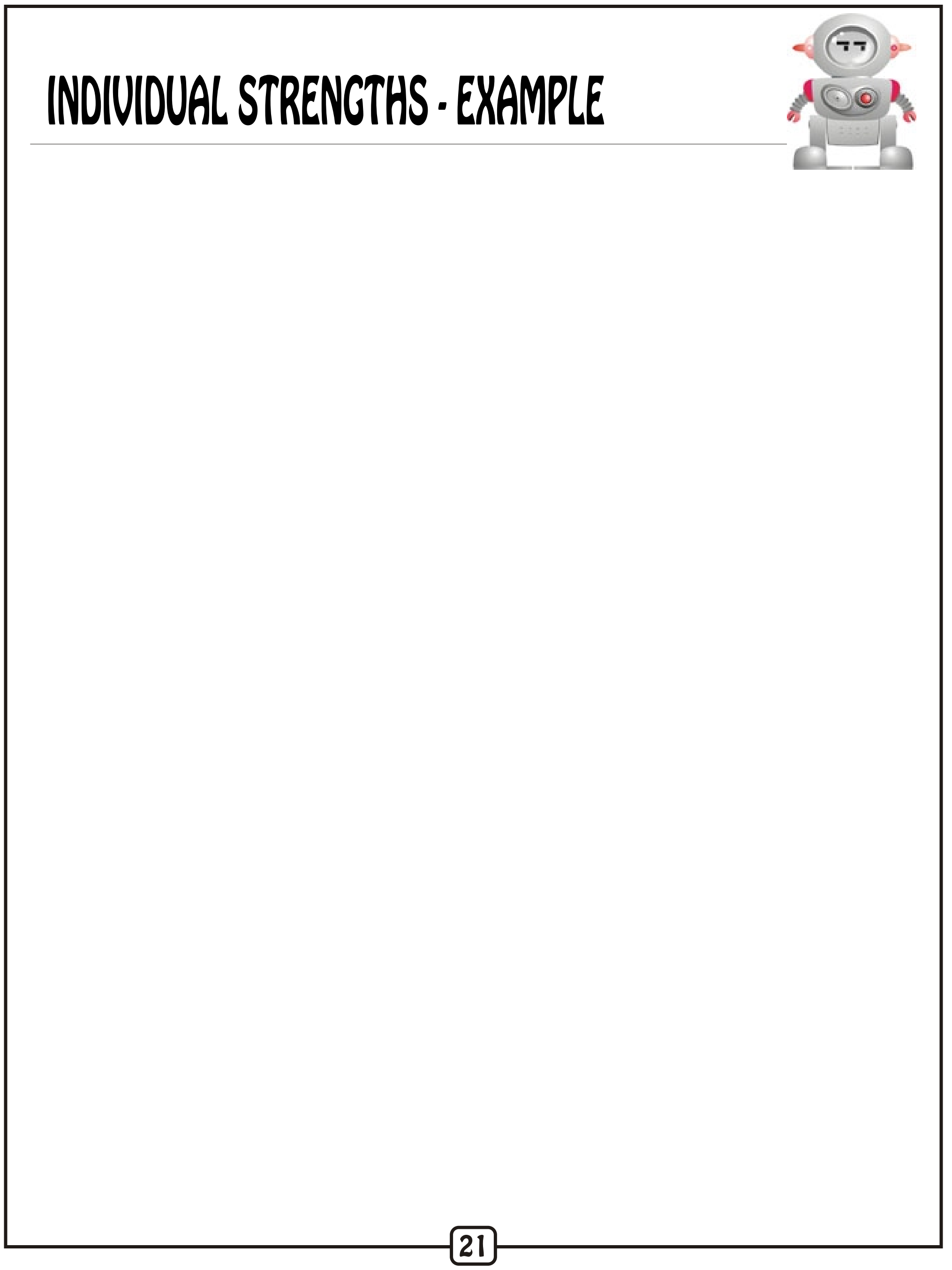


